\title{
O declínio da supremacia do interesse público sobre o particular com a constitucionalização do direito administrativo
}

The decline of the supremacy of the public interest over the private interest with the constitutionalization of administrative law

Karla Fernandez Gomes ${ }^{1}$

\section{RESUMO}

Este trabalho analisou o princípio da supremacia do interesse público sobre o particular em face da consti-tucionalização do direito administrativo, buscando verificar a viabilidade da regra de prevalência que ele enuncia no contexto do Estado Democrático de Direito. Assim, para a compreensão da problemática, foi efetuada uma pesquisa bibliográfica, em livros e artigos que versam acerca do tema de maneira direta ou indireta. Ao final, concluiu-se que o ambiente democrático acarreta uma postura ativa do Estado na har-monização dos interesses da sociedade, o que enseja a aplicação do postulado da proporcionalidade. Lo-go, a ideia de supremacia de interesse público sobre o particular é incompatível com a democracia, bem como com a dignidade humana, fundamento da República Federativa do Brasil. Isso porque a positivação dos direitos e garantias fundamentais na Constituição não apenas implica limitação estatal no que tange ao dever de não os infringir e os salvaguardar mas também lança para o Estado o dever de efetivação desses valores, o que transmuda a antiga compreensão de interesse público.

Palavras-chave: Supremacia do interesse público sobre o particular. Constitucionalização do Direito Ad-ministrativo. Direitos e garantias fundamentais. Proporcionalidade.

1 Mestra em Direito Constitucional pelo Programa de Pós-graduação em Direito Constitucional - PPGD da Universidade de Fortaleza (Nota 6 pela CAPES). Especialista em Direito Processual pelo Centro Universitário 7 de setembro - UNI7, advogada, assessora administrativa da 6 a Procuradoria de Contas do Tribunal de Contas do Estado do Ceará. E-mail: karlafernandezg@hotmail.com 


\section{ABSTRACT}

This paper analyzed the principle of the supremacy of the public interest over the private interest in view of the constitutionalization of administrative law, seeking to verify the viability of the rule of prevalence that it enunciates in the context of the Democratic State of Law. Thus, in order to understand the problem, a bibliographic search was carried out, in books and articles that deal with the topic directly or indirectly. At the end, it is concluded that the democratic environment leads to an active posture of the State in harmonizing society's interests, which leads to the application of the principle of proportionality. Therefore, the idea of public interest supremacy over the private is incompatible with a democracy, as well as with human dignity, foundation of the Federative Republic of Brazil. This is because the positivation of fundamental rights and guarantees in the Constitution not only implies a state limitation about its duty of not infringing and saving them, but also imposes on the State the duty to enforce these values, which transmutes the old understanding of public interest.

Keywords: Supremacy of the public interest over the private interest. Constitutionalization of Administra-tive Law. Fundamental rights and guarantees. Proportionality.

Recebido: 28-01-2021

Aprovado: 16-03-2021

\section{INTRODUÇÃO}

Com o surgimento do Estado de Direito como meio regulatório da sociedade, a partir da sujeição de todos, inclusive do Estado como instituição, aos ditames legais, inaugurou-se o império da lei de modo que o Poder Público não estaria apenas limitado pelas disposições normativas, mas teria por dever perseguir os interesses tutelados pela ordem legal instituída, notadamente com o reconhecimento da supremacia do texto constitucional, que 
impôs ao Estado o dever de assegurar os direitos e garantias fundamentais.

Neste diapasão do Estado Constitucional de Direito, deu-se uma reviravolta no campo do direito administrativo, uma vez que este, antes erigido e pensado a partir da legalidade restrita, agora via-se diante do comando de viabilizar a concretização dos valores constitucionais de modo que da legalidade passou-se à noção de juridicidade.

No entanto, no âmbito da função administrativa no acesso da legalidade à juridicidade verificar-se-ia um "fosso" que dificultaria a efetivação dos comandos constitucionais; é que, de fato, a Administração Pública do Brasil, efetivamente, ainda desconhecia a própria legalidade, considerando décadas de atuação com esteio em um viés autoritário que fundamentaram a defesa de algumas "bandeiras", entre as quais: a supremacia do interesse público sobre o particular.

Assim, junto com o fenômeno de superação do positivismo, com o retorno dos valores ao campo do direito por meio, no Brasil, da Constituição Federal de 1988, o Poder Público deveria perpassar pela transição do autoritarismo e do patrimonialismo para o ambiente democrático e o compromisso com a gestão pública.

Diante da constatação de que o Poder Público deve implementar os comandos constitucionais, quando a Constituição Federal de 1988 enuncia, de maneira extensa, um rol de direitos e garantias fundamentais que, em grande maioria, possuem natureza de direitos individuais, a noção da supremacia do interesse público sobre o interesse particular passou a ser repensada, sobretudo com o reconhecimento da dignidade da pessoa humana como fundamento da República Federativa do Brasil.

Portanto, a presente pesquisa, almejando compreender esse "choque" entre os direitos e garantias fundamentais e o princípio da supremacia do interesse público sobre o particular, analisará a ideia de supremacia do interesse público frente ao contexto do Estado Democrático de Direito, em especial partindo da repercussão da Constituição Federal de 1988 sobre a seara do direito administrativo. 
Dessa forma, primeiramente, analisar-se-á a ideia da supremacia do interesse público a partir de aspectos gerais, como procedência e evolução. Na sequência, realizar-se-á um exame quanto à dicotomia entre regras e princípios; seguindo com o debruçar-se acerca da caracterização normativa da supremacia do interesse público e de uma investigação pertinente à técnica da ponderação ou sopesamento. Por último, realizar-se-á um contraponto entre a juridicidade no direito administrativo e o princípio da supremacia do interesse público sobre o particular. Logo, almeja-se responder aos seguintes questionamentos: poderia a ideia de supremacia do interesse público sobre o particular conviver com a ordem democrática? Seria esse princípio compatível com o fundamento da dignidade da pessoa humana?

Para tanto, realizou-se um estudo descritivo analítico do tema proposto, por meio de pesquisa bibliográfica em trabalhos publicados em livros e artigos que dispõem acerca do objeto desta pesquisa de maneira direta ou indireta, tendo por escopo informar e possibilitar o desenvolvimento de um posicionamento crítico.

\section{BREVE ANÁLISE ACERCA DA IDEIA DE SUPREMACIA DE INTERESSE PÚBLICO SOBRE O PARTICULAR}

A ideia de supremacia de interesse público, pela doutrina tradicional, é concebida como um pilar de sustentação do direito administrativo, uma vez que seria ela, unida à concepção da indisponibilidade do interesse público, a razão que fundamentaria a existência do regime jurídico-administrativo que enuncia prerrogativas e sujeições à Administração Pública. Ademais, para parte da doutrina, ela é compreendida como justificativa do próprio fim do Estado, na perspectiva do bem comum, da vontade da geral ou do interesse majoritário.

Como exemplo, cita-se o pensamento de Celso Antônio Bandeira de Mello (2015, p. 56-57), que, ao abordar os princípios da supremacia 
do interesse público e da indisponibili-dade do interesse público, enuncia que a relevância destes reside na percepção que o próprio ordenamento jurídico na seara administrativa os instituiu como um cerne do sistema, reves-tindo-os de importância fundamental para este ramo do direito.

Contudo, com o fenômeno da constitucionalização do direito, a qual, no Brasil, deu-se com o advento da Constituição Federal de 1988, haveria uma reviravolta na ciência jurídica, mas pode-se dizer que, no âmbito do direito administrativo, a obediência aos comandos constitucionais representaria um total repensar desse ramo do direito.

Isso se deve ao fato de, conforme bem destaca Maria Sylvia Zanella Di Pietro (2005, p. 1), o direito administrativo não ter sido, nos primórdios, proposto pela sujeição à lei, mas por verdadeiras imposições do Poder Executivo, já que seu surgimento, que ocorreu na França, decorreu de regras erigidas por esse poder para o controle de sua atividade com o viés fincado no autoritarismo, visto que decorreu de uma elaboração pretoriana. Tal origem deixou traços que dificultam o avanço devido do direito administrativo em respeito aos comandos constitucionais.

Com o advento da Constituição Federal de 1988, como bem destaca Gustavo Zagrebelsky (2011, p. 33-34), passou-se do Estado de Direito para o Estado Constitucional de Direito, uma vez que, ante a supremacia das normas constitucionais, toda e qualquer norma estaria sujeita às disposições constitucionais, sob pena de ser desprovida de vinculatividade. Assim, a Constituição passa a determinar todo o ordenamento, condicionando-o aos fins nela previstos.

Desse modo, com o reconhecimento da supremacia do texto constitucional, que estipulou diversos deveres ao Poder Público, notadamente quanto ao implemento de políticas públicas para concretização de direitos e garantias fundamentais, a atividade da Administração Pública passaria a voltar-se para o administrado, ou seja, para a relação travada com este, de forma que a visão de "autoridade" estaria se transmudando para a de "servidor". 
Por fim, mais decisivo do que tudo para a constitucionalização do Direito Administrativo foi a incidência no seu domínio dos princípios constitucionais - não apenas os específicos, mas sobretudo os de caráter geral, que se irradiam por todo o sistema jurídico. Também aqui, a partir da centralidade da dignidade humana e da preservação dos direitos fundamentais, alterou-se a qualidade das relações entre Administração e administrado, com a superação ou reformulação de paradigmas tradicionais. [...]. (BARROSO, 2012, p. 49)

É que com o Estado Democrático de Direito não há como se defender mais a compreensão do Poder Público por si só, pois o real titular do poder é o povo; dessa forma, a função do Estado não se restringe a garantir a ordem legal, pois há o dever de assegurar a concretização dos valores erigidos pelo povo como os devidos a todos pela ordem social instituída no texto constitucional.

Nesse contexto, consagra-se a ideia de juridicidade que representa exatamente que o Poder Público não está apenas vinculado ao princípio da legalidade estrita, mas aos comandos constitucionais que submetem, diante da supremacia da Constituição, a própria lei. Nesse sentido, Gustavo Binenbojm (2008, p. 7) salienta que: "[...] a Constituição, e não mais a lei, passa a situar-se no cerne da vinculação administrativa; [...].".

Dessa maneira, com a constitucionalização do direito, ou seja, com o reconhecimento da hierarquia da Constituição em face das demais normas do ordenamento, o regime jurídico-administrativo encontraria respaldo nos deveres impostos pelo Constituinte ao Poder Público, uma vez que estes acabam por, além de representar sujeições à Administração Pública, fundamentar a concessão de certas prerrogativas a esta, a fim de viabilizar a própria persecução dos fins constitucionais.

Portanto, no Estado Democrático de Direito, o regime jurídico-administrativo encontra fundamento na juridicidade, e não em uma dita supremacia do interesse público sobre o particular; afinal, pelo princípio 
democrático, implementar o bem comum não corresponde a atender a um pensamento majoritário, mas à harmonização dos interesses de maneira a garantir a igualdade que permeia a sociedade democrática, ou seja, a certeza que, perante o Estado, cada indivíduo possui igual relevância. Afinal, cabe ressaltar que o art. $1^{\circ}$, inciso III, institui a dignidade da pessoa humana como um dos fundamentos da República Federativa do Brasil, sendo um comando que orienta todo o sistema jurídico vigente.

Destarte, considerando a passagem da legalidade para a juridicidade, é necessário investigar a viabilidade do princípio da supremacia do interesse público sobre o particular, inclusive avaliando, pela perspectiva epistemológica, o seu enquadramento como princípio ou como outra espécie normativa. Para tanto, passa-se ao próximo tópico.

\section{DICOTOMIA PRINCÍPIOS E REGRAS}

As normas são os instrumentos pelos quais se expressam determinações e valores consagrados em uma dada ordem legal, visando regular a convivência de uma sociedade, de forma a promover ordem e pacificação social, bem como, em um sistema democrático, a igualdade e a justiça. Logo, são os meios pelos quais a ciência jurídica vem a se expressar socialmente.

Constata-se que há mais de uma espécie de norma, uma vez que, quando da sua aplicação, verificam-se comportamentos distintos pela própria qualidade do que elas tutelam. Dessa forma, fala-se em norma-princípio e norma-regra. Robert Alexy (2015, p. 90-91), ao voltar-se para a questão, explica que as regras seriam as normas que trazem em si determinações que devem ser observadas; já os princípios consagram comandos de otimização, isto é, que devem ser aplicados da melhor maneira possível diante do caso concreto, o que implica a possibilidade de serem cumpridos em diferentes graus.

A questão reside no fato de que as regras e os princípios representam razões necessárias à manutenção do ordenamento jurídico, mas são 
espécies normativas distintas, uma vez que o princípio compulsa como um valor que foi erigido como norma, sendo assim uma razão que não pode ser afastada definitivamente da ordem instituída sob pena de comprometê-la. Já as regras são necessárias, mas podem vir a ser revogadas ou, ainda, subsistirem com a formulação de uma dada cláusula de exceção, haja vista que as regras seguem da lógica da aplicação do tudo ou nada.

Por isso, Alexy (2015, p. 91), apesar de reconhecer que os princípios, normalmente, expressam comandos dotados de maior generalidade, explica que a diferença entre princípio e regra se trata de uma distinção qualitativa, não se resumindo a uma mera verificação literal quanto à generalidade ou não do texto normativo.

Considerando que a diferenciação entre regras e princípios possui razão que supera aspectos semânticos, Manuel Atienza e Juan Ruiz Manero (2009, p. 63) explicam que justamente por os princípios possuírem uma densidade normativa mais abrangente (enunciados normativos mais gerais) terminam por alcançar um maior número de contextos fáticos, o que representa que, por terem uma conotação mais explicativa do que as regras, são dotados de uma extensão maior no campo da justificação.

Humberto Ávila (2005, p. 9) enuncia que os princípios possuem uma propensão finalística, o que os distingue das regras que resultam em comandos diretos de regulação de comportamentos. Ele, ainda, demonstra a diferença dessas espécies normativas devido à figura do postulado, ao esclarecer que este se configuraria como a razão que deve ser considerada na aplicação das demais normas - regras e princípios -, funcionando como verdadeira cláusula de orientação, modulando as formas de aferição dos raciocínios e argumentações concernentes às normas quando da aplicação destas nas situações fáticas. Assim, considerando a unidade da ordem legal, as regras e princípios devem encontrar consonância com os postulados, ao passo que, quando da aplicação das normas, os postulados e as normas possam coexistir. 
Dessa forma, diante da distinção entre regras, princípios e postulados, será que a supremacia do interesse público sobre o particular, realmente, poderia ser compreendida como um princípio ou como outra espécie normativa? Almejando responder a esse questionamento, passa-se à análise da sua caracterização normativa.

\section{A SUPREMACIA DO INTERESSE PÚBLICO E SUA CARAC- TERIZAÇÃO NORMATIVA}

Inicialmente, ressalte-se que não há previsão expressa no ordenamento pátrio acerca desse princípio. Conforme destacado, ele é defendido como um princípio implícito a partir de uma noção que se constituiria como pilar do direito administrativo.

De fato, com base em uma análise epistemológica é possível verificar que a supremacia do interesse público não se configura como norma-princípio, uma vez que princípios devem coexistir para a subsistência do Estado Democrático de Direito, razão pela qual, diante de colisões, precisam ser ponderados, e o princípio da supremacia do interesse público sobre o particular já indica uma prevalência de per si.

Assim, quando viesse a colidir com direitos e garantias fundamentais, certamente, implicaria a inobservância destes, dado que a dignidade humana se constitui como o fundamento cerne dos direitos e garantias fundamentais; logo, estes representariam interesse particular. Humberto Ávila (2007, p. 10) destaca que a supremacia do interesse público sobre o particular se revela como uma regra de prevalência abstrata diante de uma colisão, ou seja, foge à lógica das normas-princípios que possuem caráter prima facie.

Dessa forma, torna-se evidente que a supremacia do interesse público sobre o particular não pode ser reconhecida como princípio, pois apenas possui o caráter da generalidade do seu texto, mas não detém o caráter qualitativo que é inerente à norma-princípio, tendo em vista que 
ela não se configura como valor imprescindível ao ordenamento jurídico vigente, já que haveria clara contradição em uma ordem constitucional que erigiu a dignidade da pessoa humana como o seu fundamento, se esta viesse a calmar/defender, ao mesmo tempo, a existência da supremacia do interesse público sobre o particular.

Com efeito, nota-se que não há como conciliar no ordenamento jurídico um "princípio" que, ignorando as nuances do caso concreto, preestabeleça que a melhor solução consubstancia-se na vitória do interesse público. O "princípio" em si afasta o processo de ponderação, fechando as portas para os interesses privados que estejam envolvidos. Dê-se destaque, outrossim, ao fato da fórmula preconcebida presente no "princípio" ir de encontro ao dever de fundamentação ("dever de explicitação das premissas") a que sujeitam os Poderes do Estado. (BINENBOJM, 2005, p. 65)

Além do mais, no regime democrático não é possível erigir supremacia de interesses frente a outros, posto que este se pauta pela equidade na participação; razão pela qual todos os interesses devem ser igualmente considerados e harmonizados.

Por sua vez, a supremacia do interesse público sobre o particular também não pode ser tida como regra, uma vez que, apesar de representar uma determinação passível de aplicação direta, como destacado, não há previsão legal no ordenamento jurídico que a enuncie. Desse modo, resta indagar se, pelo viés democrático, esse dito princípio não seria um postulado de maneira que teria a função de orientar a aplicação das demais normas.

Pensando na questão epistemológica/formal do ordenamento jurídico, até seria possível compreendê-lo como postulado; porém, a partir de uma nuance material, atesta-se que também se torna inadequado considerá-lo como postulado, em razão de que o direito administrativo não se encontra mais vinculado à legalidade estrita, mas sim à juridicidade. Além disso, considerando o próprio regime democrático, que tem sua plena efetivação por uma lógica dialógica, defender um dito enunciado normativo que se 
aproxima bem mais de um dogma, tanto que não se sustenta de maneira harmônica com o ordenamento posto, não seria racionalmente aceitável.

E o que pode e deve ser dito relativamente a esta segunda ques-
tão é que um postulado explicativo do Direito Administrativo
não pode ser uma regra de prevalência, mesmo que essa prefe-
rência seja "apenas" abstrata e relativa. Ao contrário de uma re-
gra de preferência, poder-se-ia falar sobre o bem comum como
idéia por detrás das normas e dos fins estatais, mas que repre-
sentaria a unidade de uma multiplicidade de interesses públicos
verificáveis no Direito e na sociedade (o que terminaria, por via
diversa, por corroborar o aqui formulado postulado da recipro-
cidade, em vez do "princípio da supremacia") [...]. (ÁVILA,
2005, p. 23-24)

Dessa maneira, considerando que a Constituição Federal de 1988 caracteriza-se como garantista, já que inaugurou ordem que veio limitar o Poder do Estado diante dos valores caros à subsistência humana, prevendo expressamente o rol de direitos e garantias fundamentais, seria um contrassenso levantar como postulado dessa ordem constitucional a supremacia do interesse público sobre o particular.

Contudo, parte da doutrina, de fato, defende que ele encontraria fundamento no próprio texto constitucional na medida em que possui respaldo no princípio democrático, uma vez que o interesse público seria a composição dos interesses individuais que devem ser tutelados pelo Estado, ante o bem comum e a vontade da maioria. Nesse sentido, Alice Gonzalez Borges (2011, p. 10-13) entende que os direitos fundamentais se configuram também como interesse público, razão pela qual não haveria um antagonismo entre o interesse público e o particular, sendo possível defender a supremacia do interesse público, dado que garantir um direito fundamental, ainda que a um indivíduo, seria interesse público.

No entanto, como demonstrado, a supremacia do interesse público sobre o particular não consegue se encaixar em nenhuma das espécies normativas - princípios, regras e postulados -, haja vista que a noção de 
supremacia do interesse público sobre o particular foi pensado quando o Estado detinha uma maior carga autoritária, mas, a partir da constitucionalização do direito e do Estado Democrático, não há que se arvorar de uma dita supremacia do interesse público sobre o particular para garantir os valores erigidos constitucionalmente pelo povo e para o povo, uma vez que, para tanto, basta-se imprimir eficácia aos comandos constitucionais, o qual constitui o real papel do Estado.

Defender a supremacia do interesse público sobre o particular abre margem para que a Administração Pública, valendo-se do seu poder discricionário, venha a erigir, sobre essa escusa, a implementação de valores que fogem aos reais fins já definidos pela Constituição como o verdadeiro interesse público, e isso se deve à generalidade da própria conceituação de interesse público. Nesse sentido, bem leciona Paulo Ricardo Schier (2007, p. 163):

A conclusão, desde já adiantada para facilitar a clareza da exposição, dá-se no sentido de que a assunção prática da supremacia do interesse público sobre o privado, como cláusula geral de restrição de direitos fundamentais, tem possibi-litado a emergência de uma política autoritária de realização constitucional, na qual os direitos, liberdades e garantias fundamentais devem, sempre e sempre, ceder aos reclames do Estado que, qual Midas, transforma em interesse público tudo aquilo que toca.

Com o objetivo de deixar mais clara a inviabilidade de compreender a supremacia do interesse público sobre o particular como princípio, será analisado a seguir o instrumento pelo qual os princípios são aplicados ao caso concreto, qual seja a ponderação ou o sopesamento.

\section{A TÉCNICA DA PONDERAÇÃO OU O SOPESAMENTO}

A ponderação, embora não tenha previsão expressa na Constituição Federal de 1988, consagrou-se, no Brasil, como método de exercício da hermenêutica constitucional, amplamente disseminado entre os magistra- 
dos de $1^{\text {a }}$ instância, bem como nas Cortes do país, uma vez que o controle de constitucionalidade brasileiro alberga tanto o modo concentrado quanto o difuso. Nesse contexto, faz-se mister, inicialmente, perquirir em quê, efetivamente, ela consiste.

A ponderação está, intimamente, ligada ao exercício da jurisdição, ou seja, ao meio pelo qual se expressa o direito, notadamente o de cunho constitucional, vez que poderá ser invocada pelos juízes, quando do exercício do ato jurisdicional, diante de colisão de direitos fundamentais, sobretudo considerando que o ordenamento jurídico impõe o dever de fundamentar aos magistrados.

Nesse cenário do dever de fundamentar, o julgador encontra maior impasse quando da constatação de colisão de valores fundamentais que devem subsistir em harmonia para a conservação do Estado Democrático de Direito. Exatamente, ao observar tal situação fática, Robert Alexy concluiu, no estudo da Teoria dos Direitos Fundamentais, pela força normativa dos princípios, enunciando que estes possuem aplicação direta na solução dos casos, mas com peculiaridades, visto que, embora o princípio seja norma, este não se caracteriza como regra.

Assim, com o crescimento e a aceitação da teoria da normatividade dos princípios foi, em parte, solucionado, na prática, o dever do magistrado, diante da colisão de direitos fundamentais, de responder às lides que lhe são propostas, já que, como o princípio é norma, pode ser invocado como critério de fundamentação da decisão, atendendo à máxima constitucional de que a validade do julgamento pressupõe a observância do dever de motivar, pela especificação do fundamento (regra ou princípio) que o permitiu cunhar aquela decisão e pelos motivos pelo qual afastou as outras normas passíveis de incidência ou argumentadas pela defesa.

Portanto, com base na constatação da normatividade dos princípios, na preponderância destes nas fundamentações jurídicas e na verificação que os direitos fundamentais, que compõem a base de um Estado Democrático de Direito, constituem-se, comumente, como normas-princípios, 
indispensável é compreender como proceder frente à colisão de princípios.

Diante de um conflito de regras, a solução para este é relativamente simples, já que, conforme Alexy (2015, p. 92-93), tem por resultado a disposição de uma cláusula de exceção em uma situação específica, à qual a regra não se adéqua, ou a declaração da invalidade de uma das normas. Já ao se deparar com a colisão de princípios, o julgador, de fato, encontra-se diante de um impasse, pois são apresentados a ele dois valores igualmente preponderantes para a guarda do ordenamento jurídico.

Nessa situação, é evidente que o juiz, para dar a resposta à qual está obrigado, como antes mencionado, terá de, certamente, concluir pela primazia de algum dos princípios, o que, para a estrutura do Estado Democrático de Direito, seria possibilitar "rachaduras" em garantias individuais e princípios cernes para a sua sustentação.

A técnica da ponderação ou o sopesamento trata-se de teoria criada como meio de solução de colisão de normas-princípios de maneira a garantir que os valores consagrados nessas espécies normativas, vindo a colidir, sejam preservados no ordenamento. Para tanto, haverá uma aferição das condições fáticas e jurídicas do caso concreto a fim de estabelecer que princípio deve prevalecer sob essas dadas condições.

Desse modo, Robert Alexy (2015, p. 99) formulou a lei de colisão explicando que, havendo choque de princípios, haverá necessariamente de se concluir pela prevalência de um deles, mas, como se trata de normas que não podem ser afastadas do ordenamento, essa prevalência dar-se-á apenas diante das condições aferidas naquele caso, as quais compulsam como elemento que permite chegar à conclusão de que, por exemplo, o princípio " $\mathrm{K}$ " deverá prevalecer; formulando-se, assim, a regra do caso concreto que, em suma, representará considerando as condições " $\mathrm{D}$ ”, que o princípio " $\mathrm{K}$ " deve prevalecer frente ao princípio "A".

No entanto, a ponderação para Alexy $(2015$, p. 176) não se restringe à aplicação da lei de colisão, pois ele defende que esta resta completa quando somada à teoria da argumentação jurídica racional, vez que tal te- 
oria viabiliza a fundamentação da regra do caso extraída da lei de colisão, a partir do emprego da racionalidade pela correção, que para Alexy (2005, p. 225-226) se implementa pela lógica do discurso motivado.

Desse modo, para que o Estado possa garantir a máxima efetividade aos direitos fundamentais é salutar que o Poder Judiciário, de maneira eficaz, consiga concluir pela regra a ser aplicada, em um caso em concreto, depois do sopesamento de princípios. Para tanto, segundo Alexy (2015, p. 117-118), é necessária a correta aplicação da máxima da proporcionalidade em sentido amplo, que implica a aferição da adequação e da necessidade do princípio escolhido diante da situação fática analisada, bem como da proporcionalidade em sentido estrito ou sopesamento, que consiste no emprego da lei de colisão, antes explicitada.

Portanto, segundo a teoria desenvolvida por Alexy, ante a colisão de direitos fundamentais, a aplicação da técnica da ponderação possibilita a extração de uma regra aplicável ao caso específico; regra essa que não significa a exclusão ou diminuição valorativa de um dos direitos fundamentais envolvidos, mas, tão somente, o afastamento dele dentro de certas condições fáticas e jurídicas, o que somente é possível diante do desenvolvimento de apreciação e fundamentação jurídica das particularidades do caso concreto.

Vale destacar que há várias críticas e posicionamentos contrários à técnica da ponderação desenvolvida por Robert Alexy, porém fogem à seara do presente trabalho; apenas a explicitação da sua conceituação é necessária para a compreensão de que não é possível calmar pela aplicação do sopesamento como defesa de que a noção de supremacia do interesse público sobre o particular caracterizar-se-ia como norma-princípio.

É que a partir da compreensão da ponderação resta claro que não haveria como aplicá-la na colisão do dito princípio da supremacia do interesse público sobre o particular e outro princípio que tutelasse direito individual ou mesmo uma garantia fundamental, uma vez que aquele já indicaria a superação deste; isso robustece, como antes explicado, que a 
ideia de supremacia de interesse público sobre o particular não se configura como princípio, pois no ordenamento jurídico não é possível defender a aniquilação de um princípio ou sua inafastabilidade em um caso concreto, por não existir direito absoluto.

Ademais, Robert Dworkin (2002, p. 35-36) bem destaca que os princípios se aplicam em uma dimensão de peso ou relevância, de modo que nem um princípio inviabiliza ou anula outro princípio, uma vez que os bens que eles tutelam são igualmente preponderantes para os fins propostos pelo Estado Democrático de Direito, que tem como alicerce a salvaguarda da dignidade humana.

Dessa forma, deve-se frisar que, embora haja doutrina que defenda a aplicação indistinta da ponderação ao princípio da supremacia do interesse público sobre o particular, esse entendimento compulsa como erro, visto que o sopesamento trata-se de técnica de solução de colisão de princípios, de modo que não há como falar em ponderação entre regras ou entre choque de princípio e regras. Humberto Ávila (2009, p. 190), alertando quanto a essa confusão entre as espécies normativas por parte da doutrina, assevera: "Reitere-se: as regras e os princípios desempenham funções diferentes, não se podendo falar, portanto, da primazia de uma norma sobre outra. [...]". É que princípios e regras são espécies normativas que, juntos, compõem o ordenamento jurídico vigente, cada um com sua particularidade e sua contribuição.

Além do mais, defender a ponderação de um dado interesse público secundário que tutelasse uma norma-princípio, como a função social da propriedade, e um princípio que protege um bem particular, como o direito fundamental à propriedade privada, não haveria que se falar de aplicação da supremacia do interesse público sobre o particular, pois, no caso concreto, apenas haveria colisão de dois princípios que encontram previsão no texto constitucional, cabendo, assim, o emprego do postulado da proporcionalidade (adequação, necessidade e ponderação). 
Logo, atesta-se que se constitui como equívoco tentar buscar soluções para as dificuldades verificadas na compreensão do "princípio" da supremacia do interesse público sobre o particular na técnica da ponderação ou sopesamento, como fez Alice Gonzalez (2011, p. 18), sobre o fundamento que, inclusive, a persecução dos direitos fundamentais seria interesse público, haja vista que não há como defender aplicação de ponderação se não houver colisão entre princípios e, como já demonstrado, a supremacia do interesse público não se configura como norma-princípio.

Dessa forma, se a supremacia do interesse público sobre o particular não compulsa como princípio, tampouco como regra ou postulado, no que constituiria a noção de supremacia do interesse público sobre o particular. É o objeto de análise do próximo tópico.

\section{A JURIDICIDADE NO DIREITO ADMINISTRATIVO E A SUPREMACIA DO INTERESSE PÚBLICO SOBRE O PARTICULAR}

A juridicidade, como já explicado, representa a passagem da submissão da Administração Pública à legalidade estrita para a sujeição do Poder Público aos comandos constitucionais; logo, essa constatação decorre da constitucionalização do direito administrativo. No Brasil, tal movimento deu-se com a Constituição Federal de 1988, que, ao representar a instauração do Estado Democrático de Direito, além de limitar o Poder Estatal, colocou o Estado como o grande responsável pela eficácia dos valores erigidos pelo povo como indispensáveis à subsistência da ordem.

Nesse sentido, bem destaca Diogo de Figueiredo Moreira Neto (2012, p. 21) que o fundamento axiológico da passagem do Estado de Direito para o Estado Democrático de Direito é justamente a transição da legalidade para a juridicidade, uma vez que esta, além de abranger a legalidade, adiciona a necessidade de vinculação aos aspectos da legitimidade e da licitude. 
A supremacia do interesse público sobre o particular, como já demonstrado, não se enquadra diante da ordem instituída pela Constituição Federal de 1988, pois, além de não possuir previsão expressa, não pode ser tida como norma implícita por não se encaixar em nenhuma das espécies normativas reconhecidas pelo neoconstitucionalismo.

$\mathrm{Na}$ verdade, a ideia da supremacia do interesse público sobre o particular trata-se de razão remanescente do Estado Patrimonialista, erigido pelo autoritarismo, que durante séculos perdurou no Brasil, no qual o império do Poder Público esmagava direitos individuais, havendo uma total confusão entre o direito público e o direito privado; mais do que isso, uma quase inexistência deste último (BINENBOJM, 2005, p. 54).

Binenbojm (2005, p. 51) explica que a subsistência de certas particularidades no direito administrativo, como a discricionariedade; a supremacia do interesse público; as prerrogativas concedidas à Administração Pública, compulsa como a permanência de aspectos inerentes ao Antigo Regime, tendo, assim, o processo de transição da legalidade para a juridicidade na seara administrativa se configurado como instrumento para o revestimento da perpetuação de uma disparidade entre o Poder Público e o administrado, mantendo-se, ainda que de maneira velada, o princípio da autoridade.

Vale ressaltar que, como bem destacou Nelson Saldanha, a partir da análise dos espa-ços "jardim" e "praça", e, ainda, pela análise de aspectos da vida privada e pública, que, na verdade, apesar de existir a separação entre o público e o privado, verifica-se que essas esfe-ras, muitas vezes, confundem-se, e que resulta uma tarefa árdua encontrar algo totalmente público ou privado. Saldanha explica (2005, p. 38): "O sentido de tudo isso é o seguinte: somos socialmente uma imagem, que é projeção do ser real através de expletivos destinados a fixar, na dimensão pública, os caracteres da individualidade.".

Por sua vez, torna-se inegável que, com o advento da Constituição Federal de 1988, foi erigida ordem, que elevando a "bandeira" da digni- 
dade da pessoa humana e inaugurando o Estado Democrático de Direito, transmuda a noção do Estado, que de "senhor" passa a "servidor", posto que com a positivação de valores que tem por "pano de fundo" o resguardo da dignidade humana, como os direitos fundamentais, além de se sagrar a limitação do Po-der Público no sentido de não maculá-los, surge o dever de a atuação estatal voltar-se para a efetivação deles. É que: “[...] o Estado legitima-se e justifica-se a partir dos direitos funda-mentais e não estes a partir daquele. O Estado gira em torno do núcleo gravitacional dos direitos fundamentais." (SCHIER, 2007, p. 164).

Desse modo, pode-se afirmar que a definição da dignidade humana como fundamento da República Federativa do Brasil determina o repensar do que se compreende por interesse público. É que, como destaca Gustavo Binenbojm (2005, p. 68-69), com o fenômeno da constitucionalização, a própria visão do interesse público sofreu transformação, pois os fins constitucionais passam a compô-lo, gerando uma confusão no que se tinha por ideia de inte-resse público, pois uma garantia individual passa a ser interesse público.

Assim, tanto o interesse público quanto o interesse privado encontram-se imbricados no querer do Constituinte, pois ambos compõem a atuação estatal, pois, como salienta Humberto Ávila (2007, p. 13): “[...] Elementos privados estão incluídos nos próprios fins do Estado. [...].”.

Porém, ao se entender que os próprios direitos e garantias fundamentais compulsam como interesse público não implica motivo para afirmar que o princípio da supremacia do interesse público encontra razão de ser; pelo contrário, pois tal regra não possibilita a coexistência dos demais princípios na medida em que já enuncia precedência. Como afirma Humberto Ávila (2007, p. 14-22) inexiste consonância desse dito princípio com os postulados da proporcionalidade, da razoabilidade e da concordância prática, o que inviabiliza a sua subsistência no ordenamento jurídico vigente.

Desse modo, no Estado Democrático não é possível sustentar a 
ocorrência de prevalência absoluta de interesses ou mesmo de direitos fundamentais, uma vez que a democracia não tutela apenas a maioria, mas representa também o resguardo das minorias, consistindo na garantia da pluralidade de pensamentos, crenças, estilos de vida que são assegurados e harmonizados pela ordem constitucional.

E tal harmonização é justamente garantida pela observância dos postulados proporcionalidade, razoabilidade e concordância prática a fim de possibilitar que os pilares que sustentam/fundamentam o Estado Democrático de Direito, liberdade, igualdade e fraternidade, esta tida como a regra da reciprocidade (respeito mútuo), possam ser respeitados, bem como venham a galgar eficácia.

Portanto, ao se firmar o Estado Democrático de Direito descabe arguir supremacia de qualquer interesse, pois, no texto constitucional, já foram dispostos os fins escolhidos pelo povo e para povo como os relevantes para o desenvolvimento humano dentro do contexto social, cabendo, então, ao Estado, no exercício das prerrogativas que lhe são conferidas, garantir a observância e a efetividade das disposições constitucionais; e esse dever, pela constitucionalização do direito administrativo e pelo princípio democrático, constitui a razão de ser dos três Poderes.

\section{CONCLUSÃO}

Dessa forma, pelo exposto, verifica-se que o advento da Constituição Federal de 1988 implicou uma mudança significativa em todos os ramos do direito, mas, notadamente no direito administrativo, pode-se afirmar que ocorreu uma reviravolta, uma vez que a Administração Pública passou a estar vinculada ao cumprimento dos dispositivos constitucionais. Fala-se, assim, em juridicidade em vez de legalidade.

Nessa esteira, com o Estado Democrático de Direito, a Administração Pública brasileira, depois de tempos, teria de avançar do patrimonialismo para a gestão pública submetida à juridicidade, o que certamente 
acarreta uma transformação gradativa, que, inclusive, ainda se encontra em curso, uma vez que implica mudanças sociais, que, comumente, precisam de tempo para se efetivarem, por dependerem de fatores dinâmicos.

Nesse contexto, no Estado Democrático de Direito, o Poder Público tem o dever de viabilizar a observância e a efetividade dos direitos e garantais fundamentais, que são os valores definidos pelo povo como os necessários à subsistência da ordem instituída, os quais encontram fundamento na dignidade da pessoa humana.

Desse modo, torna-se incompatível a noção de preponderância do interesse público sobre o particular em um ordenamento que se funda na dignidade da pessoa humana, bem como em uma ordem democrática que implica, necessariamente, a conformação de interesses, já que, pelo postulado da igualdade, todo indivíduo possui igual relevância.

Daí porque pode-se afirmar que com a Constituição Federal de 1988, na qual a dignidade humana foi erigida como um pilar, e a democracia foi adotada como regime político, a ideia da existência de uma supremacia do interesse público sobre o particular destoa do seu fundamento humanitário e do seu dever de conformação dos interesses da maioria e da minoria; razão pela qual a Constituição determina o declínio dessa visão de supremacia de interesse público, ao reescrevê-lo a partir dos direitos e garantias fundamentais.

Ademais, a supremacia do interesse público sobre o particular não se constitui como norma-princípio ou como qualquer espécie normativa; na verdade, trata-se de resquício do patrimonialismo que se fundava na noção de autoridade.

Portanto, no Estado Democrático de Direito, o Poder Público está vinculado aos fins constitucionais, como também aos postulados da liberdade, igualdade, reciprocidade e proporcionalidade, a fim de promover uma sociedade justa e igualitária, o que enseja na necessidade de garantir a harmonização dos interesses envolvidos, sendo papel do Estado assegurar tal conformação que revitaliza o ambiente democrático. 


\section{REFERÊNCIAS}

ALEXY, R. Teoria da argumentação jurídica: a teoria do discurso racional como teoria da fundamentação jurídica. Tradução Zilda Hutchinson Schild Silva; revisão técnica Claudia Toledo. 2. ed. São Paulo: Landy, 2005.

ALEXY, R. Teoria dos direitos fundamentais. Tradução Virgílio Afonso da Silva. 2. ed. São Paulo: Malheiros, 2015.

ATIENZA, M.; MANERO, J. R. Sobre princípios e regras. Panóptica, [s. l.], v. 4. n. 3, p. 49-68, 2009.

ÁVILA, H. Moralidade, razoabilidade e eficiência na atividade administrativa. Revista Eletrônica de Direito do Estado, Salvador, Instituto de Direito Público da Bahia, n. 4, out./nov./dez. 2005. Disponível em: http:// www.direitoestado.com.br. Acesso em: 13 out. 2018.

ÁVILA, H. "Neoconstitucionalismo": entre a "Ciência do Direito" e o "Direito da Ciência". Revista Eletrônica do Direito do Estado, Salvador, Instituto de Direito Público da Bahia, n. 17, jan./fev./mar. 2009. Disponível em: http://www.revistas.unifaces.br/index.php/redu/article/ viem/836/595. Acesso em: 13 out. 2018.

ÁVILA, H. Repensando o "princípio da supremacia do interesse público sobre o particular. Revista Eletrônica sobre a Reforma do Estado (RERE), Salvador, Instituto Brasileiro de Direito Público, n. 11, set./out./ nov. 2007. Disponível em: http://www.direitodoestado.com.br/rere.asp. Acesso em: 13 out. 2018. 
BARROSO, L. R. A constitucionalização do direito e suas repercussões no âmbito administrativo. In: ARAGÃO, A. S. de; MARQUES NETO, F. A. (coord.). Direito administrativo e seus novos paradigmas. Belo Horizonte: Fórum, 2012. p. 31-63. ISBN 978-85-7700-186-6.

BINENBOJM, G. A constitucionalização do direito administrativo no Brasil: um inventário de avanços e retrocessos. Revista Eletrônica sobre a Reforma do Estado (RERE), Salvador, Instituto Brasileiro de Direito Público, n. 13, mar./abr./maio 2008. Disponível em: http://www.direitodoestado.com.br/rere.asp. Acesso em: 13 out. 2018.

BINENBOJM, G. Da supremacia do interesse público ao dever de proporcionalidade: um novo paradigma para o Direito Administrativo. Revista de Direito da Procuradoria Geral do Estado do Rio de Janeiro, Rio de Janeiro, n. 59, 2005. Disponível em: https://www.pge.rj.gov.br/comum/ code/MostrarArquivo.php?C $=\mathrm{MTUxNg} \% 2 \mathrm{C} \% 2 \mathrm{C}$. Acesso em: 16 out. 2018.

BORGES, A. G. Supremacia do interesse público: desconstrução ou reconstrução? Revista Eletrônica de Direito Administrativo Econômico (REDAE), Salvador, Instituto Brasileiro de Direito Público, n. 26, maio/ jun./jul. 2011. Disponível em: http://www.dirieitodoestado.com/revista/ REDAE-26-MAIO-2011-ALICE-BORGES.pdf. Acesso em: 13 out. 2018.

BRASIL. [Constituição (1988)]. Constituição da República Federativa do Brasil. Brasília, DF, Senado, 1988.

DI PIETRO, M. S. Z. Inovações no Direito Administrativo Brasileiro. Interesse Público - IP, Belo Horizonte, ano 7, n. 30, mar./abr. 2005. Disponível em: http://www.bidforum.com.br/bid/PDI0006.aspx?pdiCn$\mathrm{td}=50030$. Acesso em: 30 jul. 2015. 
DWORKIN, R. Levando os direitos a sério. Tradução Nelson Boeira. São Paulo: Martins Fontes, 2002.

MELlO, C. A. B. de. Curso de Direito Administrativo. 32. ed. rev. e atual. São Paulo: Malheiros, 2015.

MOREIRA NETO, D. F. Constitucionalização do direito administrativo. Revista da Procuradoria-Geral do Município de Juiz de Fora - RPGMJF, Belo Horizonte, ano 2, n. 2, p. 13-232, jan./dez. 2012.

SALDANHA, N. O jardim e a praça: o privado e o público na vida social e histórica. 2. ed. rev. e atual. Rio de Janeiro: Atlântica, 2005.

SCHIER, P. R. Ensaio sobre a supremacia do interesse público sobre o privado e o regime jurídico dos direitos fundamentais. Pensar: revista de ciências jurídicas, Universidade de Fortaleza, Fortaleza, v. NESP, p. 162172, abr. 2007.

ZAGREBELSKY, G. El derecho dúctil: ley, derechos, justicia. Tradução Marina Gascón. 10. ed. Madrid: Editorial Trotta, 2011. 